\title{
Causes for Treatment Delays in Dystonia and Hemifacial Spasm: A Canadian Survey
}

\author{
Mandar Jog, Sylvain Chouinard, Doug Hobson, David Grimes, Robert Chen, \\ Meetu Bhogal, Susan Simonyi
}

\begin{abstract}
Background: Dystonia must be accurately diagnosed so that treatment can be administered promptly. However, dystonia is a complex disorder, with variable presentation, which can delay diagnosis. Methods: Data were gathered by questionnaire from 866 patients with dystonia or hemifacial spasm (HFS) treated in 14 movement disorders centres in Canada injecting botulinum toxin, to better understand the path to diagnosis, wait times and obstacles to treatment. Results: Most participants were female (64.1\%), mean age was 58 years, and patients consulted an average of 3.2 physicians before receiving a dystonia or HFS diagnosis. Many patients (34\%) received other diagnoses before referral to a movement disorders clinic, most commonly "stress" (42.7\%). A variety of treatments were often received without a diagnosis. The mean lag time between symptom onset and diagnosis was 5.4 years. After the decision to use botulinum toxin, patients waited a mean of 3.1 months before treatment. The most common diagnoses were cervical dystonia (51.6\% of patients), HFS (20.0\%) and blepharospasm (9.8\%). Conclusions: Survey results show that diagnosis of dystonias or of HFS, and therefore, access to treatment, is delayed. An educational program for primary care physicians may be helpful to decrease the time to diagnosis and referral to a specialist centre for treatment.
\end{abstract}

RÉSUMÉ: Enquête canadienne sur les causes de retard dans le traitement de la dystonie et du spasme hémifacial. Contexte : Un diagnostic précis doit être posé pour que la dystonie soit traitée promptement. Cependant, la dystonie est une maladie complexe dont le mode de présentation est variable, ce qui peut retarder le diagnostic. Méthode : Nous avons recueilli les données au moyen d'un questionnaire administré à 866 patients atteints de dystonie ou de spasme hémifacial (SHF) qui ont été traités par injection de toxine botulique dans 14 centres de traitement des désordres du mouvement au Canada, afin de mieux comprendre le parcours diagnostic, les délais et les obstacles au traitement. Résultats : La majorité des patients étaient des femmes (64\%) et l'âge moyen était de 58 ans. Les patients avaient consulté en moyenne 3,2 médecins avant de recevoir un diagnostic de dystonie ou de SHF. Plusieurs patients (34\%) avaient reçu d'autres diagnostics avant d'être référés à une clinique des désordres du mouvement, le diagnostic le plus fréquent étant celui de "stress" (42,7\%). Différents traitements avaient souvent été administrés, sans qu'un diagnostic n'ait été posé. Le temps moyen écoulé entre le début des symptômes et le diagnostic était de 5,4 ans. Après que la décision d'employer de la toxine botulique ait été prise, les patients avaient attendu en moyenne 3,1 mois avant d'être traités. Les diagnostics les plus fréquents étaient les suivants : dystonie cervicale (51,6\% des patients), SHF (20,0\%) et blépharospasme (9,8\%). Conclusions : Les résultats de l'enquête démontrent qu'il existe un retard dans le diagnostic des dystonies ou du SHF et donc que l'accès au traitement en est retardé. Un programme d'éducation destiné aux médecins de première ligne pourrait aider à accélérer le diagnostic et la consultation dans un centre spécialisé dans le traitement de ces pathologies.

Can. J. Neurol. Sci. 2011; 38: 704-711

Dystonia has diverse causes, but ultimately results in patterned, directional and often sustained contractions of muscles that result in abnormal postures or repetitive movements. ${ }^{1}$ Precise diagnosis is essential for providing optimal therapy; however, the low prevalence of dystonia (e.g., 7.4/ 100000 men and 14.5/100 000 women for hemifacial spasm (HFS), ${ }^{2}$ 2.9-8.9/100 000 for cervical dystonia, ${ }^{3-6}$ and 1.2-13.3/ 100000 for blepharospasm ${ }^{4,5,7-9}$ results in many physicians having little exposure to it in their training or practices.

The low prevalence and the non-specific and intermittent clinical presentation can delay the diagnosis and institution of effective treatment for dystonia., ${ }^{1,-11}$ Many types of focal dystonia can be treated. ${ }^{12}$ Botulinum toxin type A injections, one of the most effective treatments for cervical dystonia, ${ }^{12,13}$ are often administered by movement disorders specialists.
Delays in diagnosis and concentration of movement disorders clinics in urban centres may limit access to treatment in Canada. In order to evaluate this, we conducted an observational study at

\footnotetext{
From the University of Western Ontario, and Movement Disorders Program (MJ), London Health Sciences Centre, London; Toronto Western Research Institute and Division of Neurology (RC), Department of Medicine, University of Toronto, Toronto Allergan Canada Inc (MB, SS), Markham; Department of Medicine, Division of Neurology (DG), The Ottawa Hospital, Ottawa, Ontario; Department of Neurology (SC), University of Montreal, Montreal, Quebec; Department of Medicine, Section of Neurology (DH), University of Manitoba, Winnipeg, Manitoba, Canada.

Received November 22, 2010. Final Revisions Submitted April 19, 2011. Correspondence to: Mandar Jog, London Health Science Centre, Movement Disorders Clinic, 339 Windermere Road, London, Ontario, N6A 5A5, Canada.
} 
movement disorders centres to understand the path to diagnosis for patients seeking treatment for focal dystonia and HFS, establish a timeline for access to treatment with botulinum toxin type A and identify hurdles to diagnosis and treatment.

\section{Materials AND Methods}

\section{Patients}

The inclusion criteria for the study were broad. All patients had received a diagnosis of dystonia or HFS and were attending a clinic at a movement disorders centre, that regularly treats patients with botulinum toxin. Some patients had attended the clinic previously and were returning for further treatment; other patients were attending for the first time. Each centre was asked to enroll up to 80 sequential patients (the study was not randomized). Patients participating in any clinical trial of botulinum toxin were ineligible.

\section{Questionnaire}

Study participants completed a one page survey consisting of 19 questions during a clinic visit (see Appendix). The Movement Disorders Survey was developed by Allergan Canada in consultation with a panel of movement disorders specialists (The Canadian Movement Disorder Survey Group Steering Committee), ISIS Digital Media Inc., Toronto, Canada, and AXON Clinical Research, Toronto, Canada.

\section{Study conduct}

The research ethics board or institutional ethics committee at each participating centre reviewed and approved the protocol before any patients were enrolled. All patients provided written informed consent before the survey was administered.

\section{Statistical analysis}

Results were compared by T-test or Chi-square test and an alpha level of 0.05 was used as a threshold for statistical significance.
A correspondence analysis was conducted with BrandMap (WRC Research Systems, Downers Grove Illinois). Categorical variables included time to diagnosis of dystonia in years $(<1 ; 1$ $6 ; \geq 7$ years) wait time for treatment with botulinum toxin in months (no wait; $1-<3 ; 3-6 ; \geq 7$ months), and distance to a movement disorder clinic in kilometers $(\mathrm{km})(<25 ; 25-50$; $\geq 51 \mathrm{~km}$ ). In a second analysis relationships between time to a final diagnosis (as above), number of doctors consulted $(0-1 ; 2$; 3 ; $\geq 4)$ and type of doctor or resource consulted (neurologist/movement disorders specialist; family doctor; other doctor; other patient resources) were evaluated for the three most common diagnoses (cervical dystonia; blepharospasm; HFS). Associations between these diagnoses, age in years (30-49; 50$64 ; \geq 65$ ), gender (male; female) and distance to the clinic (as above) were evaluated in a third correspondence analysis.

\section{RESULTS}

A total of 19 physicians from 14 movement disorders clinics in Canada conducted 886 patient surveys (range 9 to 84 surveys/investigator) between July 16, 2007 and May 27, 2008. The characteristics of study participants are presented in Table 1. The majority of survey participants were female and the mean age was 58 years.

On average, patients consulted approximately three different physicians (3.2) before the current dystonia or HFS diagnosis. Most patients had consulted a family physician $(683,77.1 \%$ ) and/or a neurologist $(650,73.4 \%)$ in an attempt to have their condition diagnosed. A smaller proportion had consulted a movement disorders specialist $(289,32.6 \%)$, chiropractor (171, $19.3 \%)$, eye care doctor $(146,16.5 \%)$ and/or a physiotherapist $(150,16.9 \%)$ during their quest to receive effective treatment. The proportion of patients who consulted the internet or other medical references $(161,18.2 \%)$, other affected patient (37, $4.2 \%)$ other person $(50,5.6 \%)$, and or a support group (21, $2.4 \%)$ was comparatively small.

The majority of patients $(527,59.5 \%)$ reported not receiving

Table 1: Characteristics of patients enrolled in the study

\begin{tabular}{l|l|c}
\hline \multirow{4}{*}{ Gender } & Characteristic & $\mathrm{N}(\%)$ \\
\cline { 2 - 3 } & Female & $225(25.4)$ \\
\cline { 2 - 3 } & Not stated & $568(64.1)$ \\
\hline \multirow{5}{*}{ Age, years } & $<25$ & $93(10.5)$ \\
\cline { 2 - 3 } & $25-34$ & $11(1.3)$ \\
\cline { 2 - 3 } & $35-44$ & $33(3.7)$ \\
\cline { 2 - 3 } & $45-54$ & $79(8.9)$ \\
\cline { 2 - 3 } Type of healthcare & $55-64$ & $236(26.6)$ \\
\cline { 2 - 3 } reimbursement & $65-74$ & $268(30.2)$ \\
\cline { 2 - 3 } & $\geq 75$ & $162(18.3)$ \\
\cline { 2 - 3 } Received botulinum toxin & Not stated & $95(10.7)$ \\
\cline { 2 - 3 } & Mean \pm SD & $2(0.2 \%)$ \\
\hline & Employer & $57.6 \pm 13.2$ \\
\cline { 2 - 3 } & Public & $423(47.7)$ \\
\cline { 2 - 3 } & Patient & $459(51.8)$ \\
\cline { 2 - 3 } & Nes & $154(17.4)$ \\
\cline { 2 - 3 } & Not stated & $829(93.6)$ \\
\hline
\end{tabular}

a Patients may have had one or more types of healthcare reimbursement coverage. 


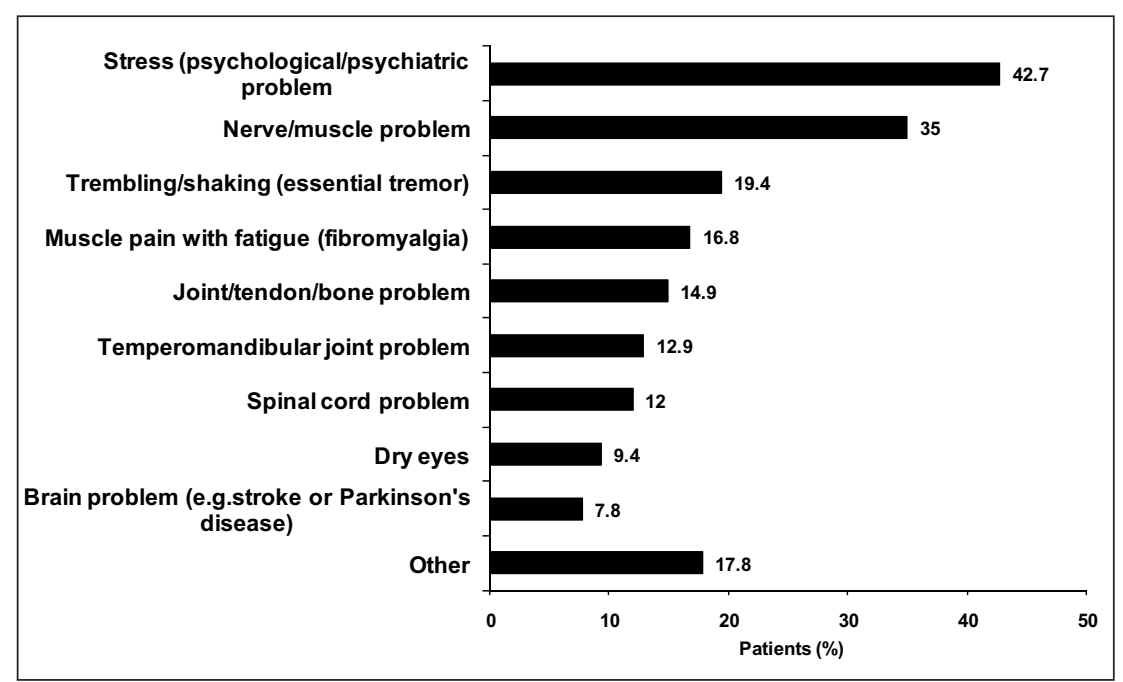

Figure 1: Diagnoses received by patients prior to the diagnosis of dystonia or HFS.

an alternative diagnosis for their movement disorder prior to the dystonia or HFS diagnosis. Among the 309 patients (34.9\%) that had received other diagnoses prior to being diagnosed with dystonia, the most common previous diagnoses were "stress" $(132,42.7 \%)$ and "nerve or muscle problem" (108, 35.0\%) (Figure 1), and nearly 20\% (59) were told there was nothing wrong.

The mean age at onset of movement disorders was 43.8 years and the average age at diagnosis of movement disorders was 48.5 years. Among patients that reported both an age of onset and an age at diagnosis, the mean lag time between onset and diagnosis was 5.4 years. The average lag time was longer in females than males (5.6 vs. 4.3 years), was longest in those aged $\geq 65$ years (7.3 years) and shortest in those aged less than 30 years (4.2 years).

The current dystonia or HFS diagnosis was made primarily by a neurologist $(564,63.7 \%)$ or movement disorders specialist $(291,32.8 \%)$. Family physicians $(82,9.3 \%)$, neurosurgeons $(47$, $5.3 \%)$, and eye care doctors $(34,3.8 \%)$ made the diagnosis in relatively few patients. The most common diagnoses for which botulinum toxin was prescribed at the participating clinics included cervical dystonia (457 patients, 51.6\%) HFS (177 patients, 20.0\%) and blepharospasm (87 patients, 9.8\%) (Figure 2 ). Females predominated within each of these three diagnoses (Table 2). Patients with cervical dystonia were younger (mean age 56 years) than those with HFS (61 years) or blepharospasm (62 years). Patients with cervical dystonia had a younger age of onset for their condition (41 years versus 49 years with HFS and blepharospasm) and a longer mean time to diagnosis (six years versus three years for HFS and four years for blepharospasm).

Prior to the diagnosis of dystonia or HFS, 543 patients $(61.3 \%)$ reported receiving previous treatment with medication (38.6\%), physiotherapy (19.0\%), chiropractic (15.7\%), botulinum toxin $(30.1 \%)$, and/or other modalities $(9.1 \%)$. Approximately one-third of patients $(35.8 \%)$ reported receiving no treatment prior to the current diagnosis. After referral to the movement disorders clinic, patients waited a mean of 3.1 months before receiving treatment with botulinum toxin. A total of 778 patients $(93.8 \%)$ received treatment within one year and $4.1 \%$ of patients (34) received treatment more than one year after the decision to use botulinum toxin was made. The most frequently reported reasons for waiting to receive a botulinum toxin injection were physician wait list $(325,53 \%)$ and time taken to complete paper work with an insurance company $(104,17.0 \%)$ (Table 3). Few patients cited lack of coverage by public drug plans $(24,3.9 \%)$, cost of treatment $(27,4.4 \%)$ or accessibility of the movement disorders clinic $(15,2.4 \%)$ as the reason for the wait.

The average distance travelled to the movement disorder clinics was $74.4 \mathrm{~km}$ and the majority of patients $(726,82 \%)$ travelled by car to their appointment (Table 4).

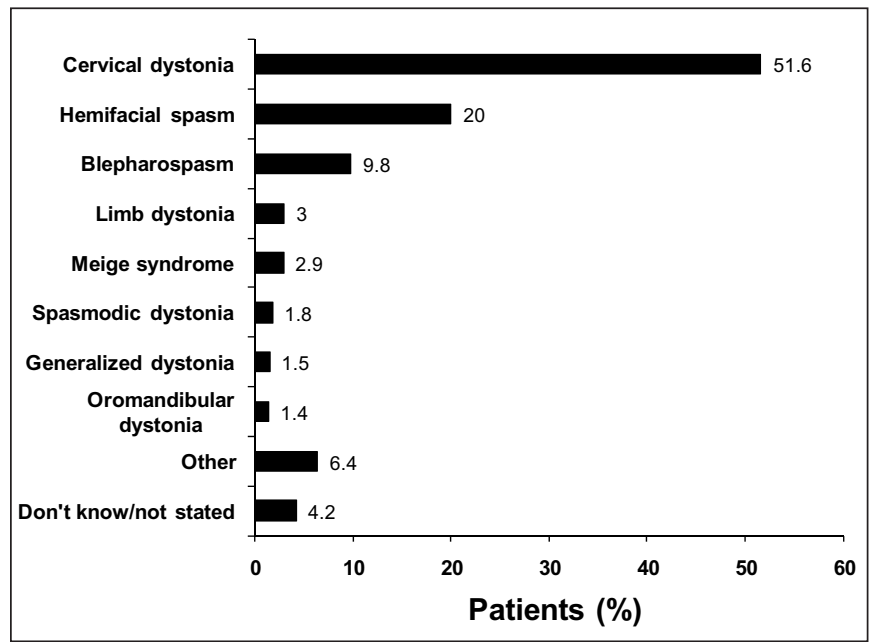

Figure 2: Current dystonia diagnoses. 
Table 2: Characteristics of patients with the most frequently reported dystonia diagnoses

\begin{tabular}{|c|c|c|c|c|c|}
\hline \multicolumn{3}{|c|}{ Characteristic } & \multirow{2}{*}{$\begin{array}{c}\begin{array}{c}\text { Cervical dystonia } \\
\mathrm{N}=457\end{array} \\
92(20.1)\end{array}$} & \multirow{2}{*}{$\begin{array}{c}\text { Hemifacial spasm } \\
\mathrm{N}=177\end{array}$} & \multirow{2}{*}{$\begin{array}{c}\begin{array}{c}\text { Blepharospasm } \\
\mathrm{N}=87\end{array} \\
24(27.6)\end{array}$} \\
\hline \multirow{3}{*}{\multicolumn{2}{|c|}{ Gender, n (\%) }} & Male & & & \\
\hline & & Female & $323(70.7)$ & $96(54.2)$ & $52(59.8)$ \\
\hline & & Not stated & $42(9.2)$ & $20(11.3)$ & $11(12.6)$ \\
\hline \multicolumn{3}{|c|}{ Mean age in years $\pm \mathrm{SD}$} & $56.4 \pm 12.7$ & $61.0 \pm 12.7$ & $62.3 \pm 13.4$ \\
\hline \multirow{7}{*}{\multicolumn{2}{|c|}{ Current age range, $\mathrm{n}(\%)$}} & $\leq 24$ & $5(1.1)$ & $3(1.7)$ & 0 \\
\hline & & $25-34$ & $18(3.9)$ & $2(1.1)$ & $2(2.3)$ \\
\hline & & $35-44$ & $47(10.3)$ & $9(5.1)$ & $8(9.2)$ \\
\hline & & $45-54$ & $129(28.2)$ & $41(23.2)$ & $13(14.9)$ \\
\hline & & $55-64$ & $145(31.7)$ & $53(29.9)$ & $26(29.9)$ \\
\hline & & $65-74$ & $77(16.8)$ & $38(21.5)$ & $23(26.4)$ \\
\hline & & $\geq 75$ & $34(7.4)$ & $31(17.5)$ & $15(17.2)$ \\
\hline \multicolumn{3}{|c|}{ Mean age at onset of symptoms of dystonia, years } & $41.3 \pm 15.8$ & $48.6 \pm 16.8$ & $49.8 \pm 15.8$ \\
\hline \multicolumn{3}{|c|}{ Mean age when dystonia was diagnosed, years } & $47.3 \pm 14.3$ & $51.8 \pm 15.8$ & $53.1 \pm 13.7$ \\
\hline \multicolumn{3}{|c|}{ Mean time to diagnosis, years } & 6.4 & 3.9 & 4.5 \\
\hline \multicolumn{3}{|c|}{ Mean distance from clinic, $\mathrm{km}$} & 79.5 & 71.7 & 71.4 \\
\hline \multicolumn{3}{|c|}{$\begin{array}{l}\text { Mean number of healthcare professionals } \\
\text { consulted prior to the diagnosis }\end{array}$} & 3.3 & 2.5 & 3.2 \\
\hline \multirow{5}{*}{$\begin{array}{l}\text { Health } \\
\text { professionals } \\
\text { consulted prior to } \\
\text { present diagnosis, } \\
\mathrm{n}(\%)\end{array}$} & \multicolumn{2}{|c|}{$\begin{array}{l}\text { Neurologist/ movement } \\
\text { disorders specialist }\end{array}$} & $388(84.9)$ & $142(80.2)$ & $66(75.9)$ \\
\hline & \multicolumn{2}{|c|}{ Family doctor } & $361(79.0)$ & $122(68.9)$ & $64(73.6)$ \\
\hline & \multicolumn{2}{|c|}{ Chiropractor } & $127(27.8)$ & $10(5.6)$ & $7(8.0)$ \\
\hline & \multicolumn{2}{|c|}{ Physiotherapist } & $114(24.9)$ & $2(1.1)$ & $3(3.4)$ \\
\hline & \multicolumn{2}{|c|}{ Eye Care doctor } & $23(5.0)$ & $48(27.1)$ & $50(57.7)$ \\
\hline \multirow{3}{*}{$\begin{array}{l}\text { Other diagnoses } \\
\text { made prior to } \\
\text { present diagnosis, } \\
\mathrm{n}(\%)\end{array}$} & \multicolumn{2}{|c|}{ Yes } & $183(40.0)$ & $41(23.2)$ & $32(36.8)$ \\
\hline & \multicolumn{2}{|c|}{ No } & $249(54.5)$ & $126(71.2)$ & $52(59.8)$ \\
\hline & \multicolumn{2}{|c|}{ Don't know/not stated } & $25(5.5)$ & $10(5.6)$ & $3(3.4)$ \\
\hline \multirow{7}{*}{ Other diagnoses } & \multicolumn{2}{|c|}{ Stress } & $86(47.0)$ & $15(36.6)$ & $10(31.3)$ \\
\hline & \multicolumn{2}{|c|}{ Nerve/muscle problem } & $69(37.7)$ & $16(39.0)$ & $6(18.8)$ \\
\hline & \multicolumn{2}{|c|}{ Tremor } & $51(27.9)$ & $3(7.3)$ & - \\
\hline & Fibr & yalgia & $34(18.6)$ & $7(7.3)$ & $3(9.4)$ \\
\hline & Join & ndon problems & $32(17.5)$ & $2(4.9)$ & $2(6.3)$ \\
\hline & $\begin{array}{l}\text { Tem } \\
\text { prob }\end{array}$ & $\begin{array}{l}\text { romandibular joint } \\
\text { n }\end{array}$ & $21(11.5)$ & $4(9.8)$ & $3(9.4)$ \\
\hline & Spin & & $32(17.5)$ & $1(2.4)$ & - \\
\hline & $\begin{array}{l}\text { Neu } \\
\text { diso }\end{array}$ & $\begin{array}{l}\text { ogist/ movement } \\
\text { rs specialist }\end{array}$ & $408(89.3)$ & $154(87.0)$ & $72(82.8)$ \\
\hline Health & Fam & doctor & $45(9.8)$ & $13(7.3)$ & $9(10.3)$ \\
\hline $\begin{array}{l}\text { professionals who } \\
\text { diagnosed present }\end{array}$ & $\mathrm{Neu}$ & urgeon & $25(5.5)$ & $16(9.0)$ & $1(1.1)$ \\
\hline dystonia, n (\%) & Phy: & therapist & $16(3.5)$ & $1(0.6)$ & - \\
\hline & Phy: & & $13(2.8)$ & - & - \\
\hline & Eye & re doctor & $6(1.3)$ & $6(3.4)$ & $17(19.5)$ \\
\hline $\begin{array}{l}\text { Received treatment } \\
\text { diagnosis }^{\mathrm{a}}\end{array}$ & rior t & oresent dystonia & $323(70.7)$ & $73(41.2)$ & $43(49.4)$ \\
\hline $\begin{array}{l}\text { Receiving botulinu } \\
\text { diagnosis }\end{array}$ & toxil & or the present dystonia & $424(92.8)$ & $168(94.9)$ & $81(93.1)$ \\
\hline
\end{tabular}

${ }^{a}$ Previous treatments included medication, physiotherapy, chiropractic interventions, and botulinum toxin injections

The correspondence analyses show that patients living 0-25 $\mathrm{km}$ or $26-50 \mathrm{~km}$ from a movement disorders clinic were more likely to receive a diagnosis in less than one year and to have shorter wait times for treatment with botulinum toxin A (either no wait, or one to three months). Alternatively, patients living more than $51 \mathrm{~km}$ from a movement disorders clinic, were more likely wait one or more years for a diagnosis and to wait three to six months for treatment.
Patients with cervical dystonia were more likely to wait seven or more years for a diagnosis and to have consulted more physicians ( $>3$ ) and patient resources than patients with HFS or blepharospasm. Patients with HFS were more likely to have a shorter time to diagnosis (less than one year), to have consulted fewer physicians (0-1), but were more likely to have consulted a movement disorders specialist (MD)/neurologist. Patients with blepharospasm were more likely to wait from one to six years to 
Table 3: Waiting times for administration of botulinum toxin injection

\begin{tabular}{|c|c|c|c|}
\hline \multicolumn{2}{|c|}{ Characteristic } & \multirow{2}{*}{$\begin{array}{c}\text { Mean time from onset of } \\
\text { symptoms to diagnosis, } \\
\text { years (n) }\end{array}$} & \multirow{2}{*}{$\begin{array}{c}\begin{array}{c}\text { Mean wait time for } \\
\text { botulinum toxin injection, } \\
\text { months }(\mathrm{n})\end{array} \\
2.6(210)\end{array}$} \\
\hline & Male & & \\
\hline Gender & Female & $4.7(568)$ & $3.3(535)$ \\
\hline \multirow{4}{*}{ Age range } & $<30$ & $4.7(24)$ & $2.4(23)$ \\
\hline & $30-49$ & $4.1(196)$ & $4.0(184)$ \\
\hline & $50-64$ & $4.3(407)$ & $3.1(383)$ \\
\hline & $\geq 65$ & $4.2(257)$ & $2.6(238)$ \\
\hline \multirow{3}{*}{$\begin{array}{l}\text { Type of healthcare } \\
\text { reimbursement } \mathrm{t}^{\mathrm{a}}\end{array}$} & Employer & $4.1(423)$ & $3.2(399)$ \\
\hline & Public & $4.1(459)$ & $3.0(429)$ \\
\hline & Patient & $5.0(154)$ & $3.3(147)$ \\
\hline
\end{tabular}

${ }^{a}$ Patients may have had one or more types of healthcare reimbursement coverage

diagnosis, to have consulted at least two physicians and were more likely to have consulted "other types of doctors/ specialists".

Patients with HFS were more likely to be male, to be aged more than 50 years, to live less than $50 \mathrm{~km}$ from a movement disorders clinic and more likely to have waited less than one year for a diagnosis. Patients with cervical dystonia were more likely to be female, to be aged 30 to 49 years and to have waited more than seven years for a diagnosis. Patients with cervical dystonia were more likely to live more than $51 \mathrm{~km}$ from a movement disorders clinic. Patients with blepharospasm were more likely to be male, to be over the age of 65 years, to have waited from one to six years for a diagnosis and to live $25 \mathrm{~km}$ or less from a movement disorders clinic.

\section{Discussion}

The results of this survey provide information on the characteristics of patients with movement disorders who present to a movement disorder clinic across Canada, the majority of whom were treated with botulinum toxin $(93.6 \%)$, and gives insight into the pathway such patients follow to receive a diagnosis of dystonia or HFS. Most of these patients had consulted a family physician and, on average, more than three physicians in total before the diagnosis was made. Thus delays in diagnosis may not be due to a lack of availability of physicians, but rather, points to the diagnostic uncertainty of initial mild clinical findings, and the nonspecific and highly variable symptoms reported by patients. The low prevalence, the lack of awareness of dystonia and the probable benefits of referring uncertain cases to specialists for assessment may also contribute to the delay. ${ }^{14}$ The diagnosis of dystonia is based on clinical diagnostic skills, ${ }^{14,15}$ and often requires the expertise of a neurologist or movement disorders specialist.

A large majority of patients had not received an alternative diagnosis prior to seeing a specialist in movement disorders. Moreover, patients who had received an alternative diagnosis

Table 4: Mode of transportation and distance travelled to movement disorders clinics

\begin{tabular}{l|l|c}
\hline \multirow{4}{*}{$\begin{array}{l}\text { Mode of transportation to } \\
\text { the clinic, n (\%) }\end{array}$} & Car & $726(81.9)$ \\
\cline { 2 - 3 } & Public transit/taxi & $106(12.0)$ \\
\cline { 2 - 3 } & Walking & $17(1.9)$ \\
\cline { 2 - 3 } & Train & $9(1.0)$ \\
\cline { 2 - 3 } & Plane & $8(0.9)$ \\
\cline { 2 - 3 } & Wheelchair bus & $7(0.8)$ \\
\cline { 2 - 3 } & Other & $14(1.6)$ \\
\cline { 2 - 3 } & Not stated & $20(2.3)$ \\
\hline \multirow{4}{*}{$\begin{array}{c}\text { Distance travelled to the } \\
\text { clinic, km }\end{array}$} & $\leq 25$ & $346(39.1)$ \\
\cline { 2 - 3 } & $26-50$ & $191(21.6)$ \\
\cline { 2 - 3 } & $51-100$ & $140(15.8)$ \\
\cline { 2 - 3 } & $101-200$ & $108(12.2)$ \\
\cline { 2 - 3 } & $201-300$ & $46(5.2)$ \\
\cline { 2 - 3 } & $>300$ & $37(4.2)$ \\
\cline { 2 - 3 } & Don't know/not stated & $18(2.0)$ \\
\cline { 2 - 3 } & Mean distance & 74.4 \\
\hline
\end{tabular}

${ }^{a}$ Calculations are based on the midpoint of the reported ranges 
were rarely told that they had dystonia. More than three-quarters of such patients had been told that their symptoms were due to stress or nerve or muscle problems. In such cases the physician may have been uncertain of the diagnosis, but believed that the patient had a psychogenic movement disorder or that psychological factors contributed to the symptoms. ${ }^{14,15}$ Even if we assume that some of these problems were recognized as dystonia or HFS, the proportion of patients who had received an accurate diagnosis appears to have been remarkably low until after referral to a neurologist or movement disorder specialist. Historically cervical dystonia and blepharospasm have been inaccurately attributed to psychogenic disorders. ${ }^{15}$ As a result of misdiagnosis or delayed diagnosis, many patients may not have received timely and specific treatment.

A substantial proportion of patients reported receiving no treatment for their symptoms prior to the dystonia or HFS diagnosis. Since the study was conducted in movement disorders clinics providing botulinum toxin, it is not surprising that patients had not previously received this mainstay of therapy for the three most common diagnoses - cervical dystonia, ${ }^{16} \mathrm{HFS},{ }^{17}$ and blepharospasm. ${ }^{18}$ Given that effective treatment is available for these individuals, our study raises the concern that the prolonged wait times to diagnosis and treatment might have had a substantial negative impact on quality of life. Dystonia is one of the most under-recognized movement disorders, ${ }^{14}$ and some patients may never obtain an accurate diagnosis and appropriate treatment.

Some patients reported receiving prior treatment, including botulinum toxin, prior to receiving their present dystonia diagnosis. The details of these treatments were not captured in the survey.

The results suggest that for patients who are eventually referred to a movement disorders specialist the wait time between the decision to prescribe botulinum toxin and the initiation of treatment is comparatively brief in the Canadian healthcare system. Once the decision to use botulinum toxin was made, treatment was provided within a mean time period of 3.1 months and $94 \%$ of patients received botulinum toxin within 1 year. The most common reason given for this relatively short wait time between diagnosis and treatment was time spent on physicians' wait lists and delays while waiting for paper work with insurance providers. Wait times due to paperwork were significantly longer in those with employer insurance plans than among those with public health insurance. Further exploration may be useful regarding ways of improving this obstacle to access. In contrast, those covered under public health care plans were more likely to experience delays due to injectors' wait lists.

Given the mean duration of time taken to arrive at a definitive diagnosis was more than five years, there is an opportunity to educate family physicians, general neurologists, and other clinicians to minimize the time to diagnosis and improve the timing of referral to a specialist treatment centre. ${ }^{19}$ Simply training more neurologists to inject botulinum toxin will not alleviate the problems identified in the survey; however, educational programs on diagnosis and treatment of dystonias, as well as informing physicians and other health care workers about the services available at specialist movement disorders clinics may shorten the time from diagnosis to treatment.
Across all patients, the type of health care insurance (public, employer-provided (private), or none) did not appear to affect wait times for treatment as $59 \%$ of patients waited less than three months, and $80 \%$ waited six months or less. However, when stratified by age, those patients aged up to 29 years and those aged 65 and older had the shortest wait times for treatment, while those aged 30 to 64 years had the longest wait times. This likely reflects the availability of public health insurance for treatment of the three most common conditions in this survey (cervical dystonia, blepharospasm, HFS) in elderly patients. Younger, working-aged patients in several regions of Canada require private insurance coverage or must personally pay for pharmaceutical treatment.

Canada is large, sparsely populated and has a decentralized health care system that is administered by provinces. Thus, the geographic areas covered by participating centres varies greatly, largely because there are no specialists experienced in the administration of botulinum toxin outside of major urban centres. Patients travelled long distances (mean $74.4 \mathrm{~km}$ one way), most often by car ( $82 \%$ of the time), to receive botulinum toxin. Given that a disproportionate number of patients with dystonia or HFS are elderly, the need to travel by car places an additional burden on caregivers, patients and the health care system. However, the challenges to maintaining expertise in the diagnosis and treatment of dystonia in the vast rural areas of Canada include the inherent complexity of the disorder and the low volume of patients in regional clinical practices. Consequently, relatively few rural-based clinicians choose to administer botulinum toxin, thus, the current centralization of expertise is likely the most practical arrangement.

The most common movement disorders reported in the survey included cervical dystonia, blepharospasm, and HFS. The proportion of patients in each of these categories was generally similar across the participating clinics. This suggests that participating physicians did not select patients by diagnostic category, but rather that the sample accurately reflects the clinical spectrum of patients with dystonia or HFS on practice rosters. The predominance of female patients is consistent with reports in the literature. As expected patients with blepharospasm were older, but were diagnosed sooner than those with other diagnoses. This may be because blepharospasm is more easily recognized and that patients were more rapidly referred to movement disorders specialists by eye care professionals. In contrast, patients with cervical dystonia present with more complex and variable symptoms, including nonspecific complaints of neck pain, and without obvious signs of torsion during the early stages of the condition. As a result the pathway to a diagnosis is less direct.

Correspondence analysis, which is commonly used in the social sciences to investigate associations between variables, revealed an association between distance travelled to the movement disorders clinic, time to diagnosis and wait time before treatment with botulinum toxin. Patients who traveled less than $50 \mathrm{~km}$ to specialist movement disorders clinics tended to have shorter times to diagnosis than those travelling further and, once the diagnosis was made, had shorter wait times before receiving botulinum toxin. In contrast those travelling more than $50 \mathrm{~km}$ to a clinic waited longer for a diagnosis and for treatment with botulinum toxin. 
Reliance on patient-reported data is an inherent limitation of this observational study. Selection bias is also a limitation of a study such as this. The study population may be representative of patients with more severe dystonia as such patients are more likely to be referred to specialist centres. Only patients referred to such centres participated in the survey, thus the study may have bias towards including patients treated with botulinum toxin. In addition, by conducting the survey in specialist centres, the patient cohort does not represent the incidence of dystonia and HFS in the general population, including those who may not have been diagnosed, have been diagnosed appropriately but were not candidates for treatment, or were not referred to a movement disorder specialist centre for further management.

\section{Conclusions}

The results of this study may be used to improve wait times for the diagnosis and treatment of dystonia in Canada. The condition appears to be often misdiagnosed, which may result in delayed access to appropriate treatments, prolonged impairment of quality of life, ${ }^{20}$ and potentially an increased burden on the health care system as patients seek help from various health care professionals. Resources should be devoted to raising awareness of dystonia and HFS among patients and the general public, by establishing support and advocacy groups, and among primary care physicians and other referring health care professionals. In particular, educational programs should be developed for the purpose of improving the ability of primary care physicians to recognize the various presentations of dystonia, manage the disorder, and to increase awareness that effective and specific treatment, when needed, is available through timely referrals to specialist centres.

\section{ACKNOWLEDGMENTS}

Members of the Canadian Movement Disorder Survey Group: Andrew Borys, MD, Deer Lodge Centre, Winnipeg, Manitoba; Robert Chen, MD, Toronto Western Hospital, Toronto, Ontario; Sylvain Chouinard, MD, Hopital Notre-Dame, Montreal, Quebec; Martin Cloutier, MD, Neuro-Rive-Sud, Greenfield Park, Quebec; Earl Consky, MD, Toronto, Ontario; David Grimes, MD, The Ottawa Hospital, Ottawa, Ontario; Doug Hobson, MD, Deer Lodge Centre, Winnipeg, Manitoba; Mandar Jog, MD, London Health Sciences Centre, London, Ontario; John Kay, MD, London, Ontario; David King, MD, Queen Elizabeth II Health Science Centre, Halifax, Nova Scotia; Scott Kraft, MD, Foothills Hospital, Calgary, Alberta; Michel Panisset, MD, Hopital Notre-Dame, Montreal, Quebec; Rick Paulseth, MD, McMaster University, Hamilton, Ontario; Alexander Rajput, MD, Royal University Hospital, Saskatoon, Saskatchewan; Ranjit Ranawaya, MD, , Foothills Hospital, Calgary, Alberta; Valerie Soland, MD, Hotel-Dieu, Montreal, Quebec; Oksana Suchowersky, MD, Foothills Hospital, Calgary, Alberta; Joseph Tsui, MD, Pacific Parkison's Research Centre; Felix Veloso, MD Pasqua Hospital, Regina, Saskatchewan. Financial support: Allergan Inc. Assistance with study design and conduct and statistical analysis: Summit Strategy group, ISIS Digital Media. Editorial Support, Blair Jarvis. Critical review, Arlene Ali, Ph.D.

\section{FinANCIAL DISCLOSURES}

Mandar Jog, MD has served as a speaker, a consultant, and an advisor on behalf of Allergan, Biovail, Merz, Novartis, and Teva and has received research funding from Allergan and Merz. Sylvain Chouinard, MD has served as a speaker and a consultant on behalf of Allergan, Merz, Novartis, and Teva, has served as an advisor on behalf of Merz, Novartis and Teva and has received research funding from Allergan and Novartis. Doug Hobson, MD has served as a speaker and an advisor on behalf of Allergan, and has received research funding from Merz. David Grimes, MD has served as a speaker on behalf of Allergan, Merz and Teva, has served as a consultant for Allergan and Teva and has received research funding from Allergan, IMPAX Pharmaceuticals, the Canadian Institute for Health Research, The National Institutes of Health, the Parkinson Research Consortium and the MJF Foundation. Robert Chen, MD has served as a speaker on behalf of Merz, a consultant for Medtronic and Teva and has received research funding from Medtronic.

Meetu Bhogal, M.Sc. and Susan Simonyi, B.Sc.RN are employees of Allergan Inc.

\section{REFERENCES}

1. Geyer HL, Bressman SB. The diagnosis of dystonia. Lancet Neurol. 2006; 5(9):780-90.

2. Auger RG, Whisnant JP. Hemifacial spasm in Rochester and Olmsted County, Minnesota, 1960 to 1984. Arch Neurol. 1990; 47(11):1233-4

3. Claypool DW, Duane DD, Ilstrup DM, Melton LJ, III. Epidemiology and outcome of cervical dystonia (spasmodic torticollis) in Rochester, Minnesota. Mov Disord. 1995; 10(5): 608-14

4. Nakashima K, Kusumi M, Inoue Y, Takahashi K. Prevalence of focal dystonias in the western area of Tottori Prefecture in Japan. Mov Disord. 1995; 10(4):440-3.

5. A prevalence study of primary dystonia in eight European countries. J Neurol. 2000; 247(10):787-92.

6. Marras C, Van den Eeden SK, Fross RD, et al. Minimum incidence of primary cervical dystonia in a multiethnic health care population. Neurology. 2007; 69(7):676-80.

7. Nutt JG, Muenter MD, Aronson A, Kurland LT, Melton LJ, III. Epidemiology of focal and generalized dystonia in Rochester, Minnesota. Mov Disord. 1988; 3(3):188-94.

8. Defazio G, Livrea P, De Salvia R, et al. Prevalence of primary blepharospasm in a community of Puglia region, Southern Italy. Neurology. 2001; 56(11):1579-81.

9. Cossu G, Mereu A, Deriu M, et al. Prevalence of primary blepharospasm in Sardinia, Italy: a service-based survey. Mov Disord. 2006; 21(11):2005-8.

10. Hallett M. Blepharospasm: recent advances. Neurology. 2002; 59(9):1306-12.

11. Jankovic J, Tsui J, Bergeron C. Prevalence of cervical dystonia and spasmodic torticollis in the United States general population. Parkinsonism Relat Disord. 2007; 13(7):411-16.

12. Jankovic J. Treatment of hyperkinetic movement disorders. Lancet Neurol. 2009; 8(9):844-56.

13. Simpson DM, Blitzer A, Brashear AM, et al. Assessment: Botulinum neurotoxin for the treatment of movement disorders (an evidence-based review): report of the Therapeutics and Technology Assessment Subcommittee of the American Academy of Neurology. Neurology. 2008; 70(19):1699-706.

14. Albanese A. The clinical expression of primary dystonia. J Neurol. 2003; 250(10):1145-51.

15. Abdo WF, van de Warrenburg BP, Burn DJ, Quinn NP, Bloem BR. The clinical approach to movement disorders. Nat Rev Neurol. 2010; 6(1):29-37. 
16. Swope D, Barbano R. Treatment recommendations and practical applications of botulinum toxin treatment of cervical dystonia. Neurol Clin. 2008; 26 Suppl 1:54-65.

17. Kenney C, Jankovic J. Botulinum toxin in the treatment of blepharospasm and hemifacial spasm. J Neural Transm. 2008; 115(4):585-91.

18. Hallett $M$, Evinger $C$, Jankovic J, Stacy $M$. Update on blepharospasm: report from the BEBRF International Workshop. Neurology. 2008; 71(16):1275-82.
19. Albanese A, Lalli S. Is this dystonia? Mov Disord. 2009; 24(12): 1725-31.

20. Hilker R, Schischniaschvili M, Ghaemi M, Jacobs A, Rudolf J. Health related quality of life is improved by botulinum neurotoxin type A in long term treated patients with focal dystonia. J Neurol Neurosurg Psychiatry. 2001; 71(2):193-9.

\section{Appendix: Sample of Questionaire}

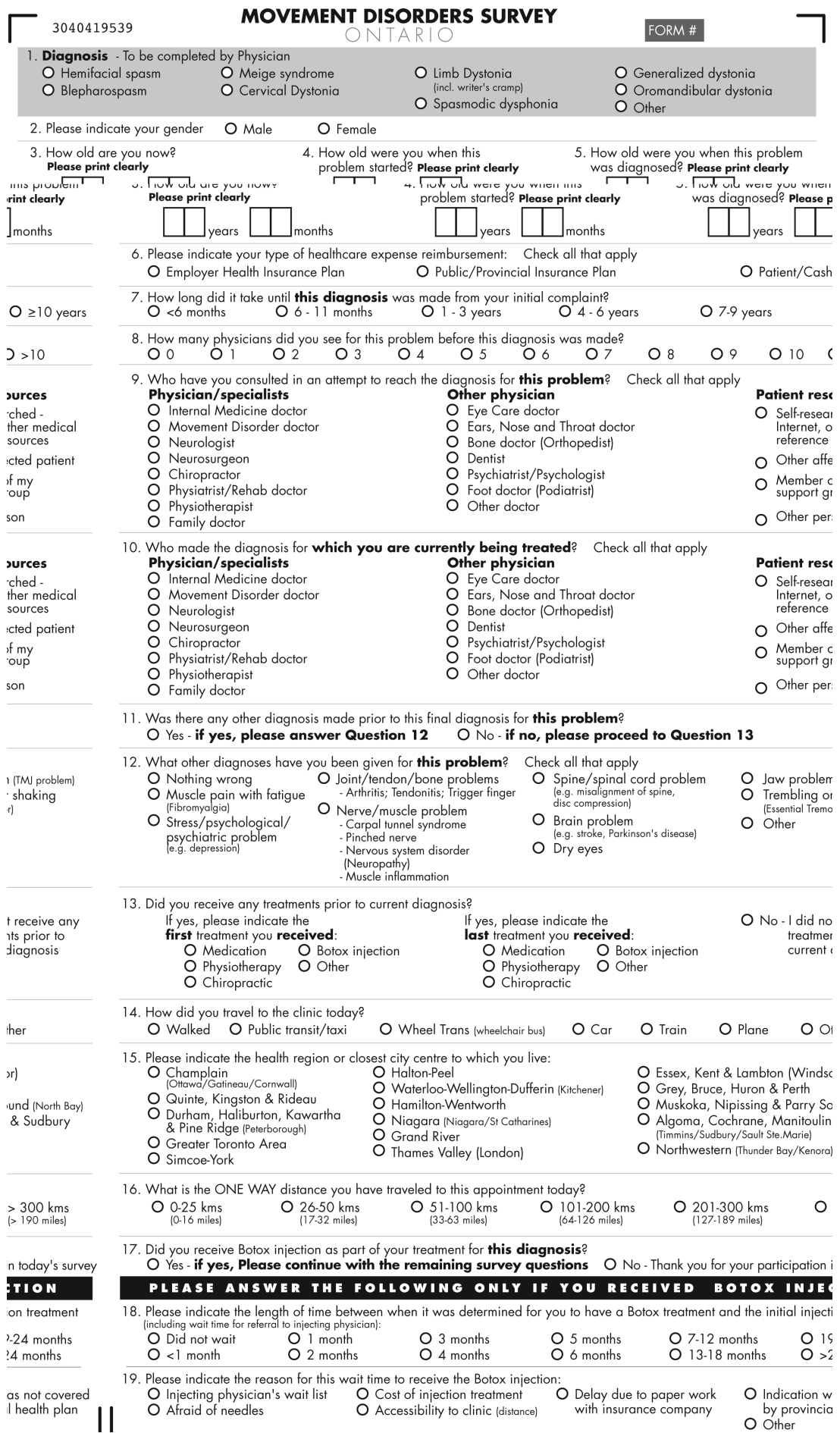

